\title{
Dakwah dan Perdebatan Seputar Pluralisme
}

\author{
Muhammad Haramain ${ }^{1}$
}

\section{A. Latar Belakang}

Pluralitas atau kemajemukan umat manusia adalah kenyataan yang telah menjadi kehendak Tuhan. Jika di dalam al-Qur'an disebutkan bahwa manusia diciptakan berbangsa-bangsa dan bersuku-suku agar mereka saling kenal mengenal dan menghargai, 2 maka manusia dengan ciri pluralitas itu pada gilirannya menjadi masyarakat yang plural berdasarkan kenyataan yang ada sekarang.

Al-Qur'an menegaskan bahwa perbedaan antara manusia dalam bahasa dan warna kulit harus diterima sebagai kenyataan yang positif, karena ia merupakan salah satu tanda-tanda kebesaran Tuhan. ${ }^{3}$ Juga terdapat penegasan tentang kemajemukan dalam pandangan dan cara hidup antara manusia yang tidak perlu diperhatikan, dan hendaknya digunakan sebagai pangkal tolak berlomba-lomba

\footnotetext{
${ }^{1}$ Makalah dipresentasikan pada Mata Kuliah Dakwah Islam Kontemporer di Pascasarjana UIN Alauddin Makassar pada hari Ahad, 12 Oktober 2014. Dosen Pengampu, Yang Amat Terpelajar; Dr. Hj. Muliaty Amin, M.A. dan Dr. Baharuddin Ali, M.A.

${ }^{2}$ QS. al-Hujurāt (49): 13

${ }^{3}$ QS. al-Rūm (30): 22
} 
menuju berbagai kebaikan dan bahwa Tuhanlah yang akan menerangkan mengapa manusia berbeda-beda, nanti ketika kita kembali kepadanya. ${ }^{4}$

Islam bahwa mencari titik temu adalah bagian yang amat penting, dan tidak boleh diabaikan. Salah satu nas yang secara sharīh menyatakan seperti ini adalah diperintahkan kepada Nabi saw untuk mendakwahkan ajaran Islam dan mengajak Ahl al-Kitāb bersatu dalam satu pandangan yang sama (kalimah sawā'), yaitu paham Ketuhanan Yang Maha Esa. ${ }^{5}$

Dakwah yang disampaikan Nabi saw, bukan saja pada ahlul kitab, tetapi kepada masyarakat plural dimana beliau menyampaikan pesan agama kepada umat agar dapat melaksanakan syariat agama secara benar dan penuh tanggungjawab sesusai dengan tuntunan Al-Qur'an dan hadis menuju terciptanya masyarakat yang damai, aman, dan sejahteran. Proses yang berkelanjutan membuat akibat setiap individu memahami sepenuhnya bahwa dakwah adalah kewajiban dengan segala tanggungjawab dan disertai dengan sebuah konsekuensi memperoleh ridha Allah.

Hakikat dakwah bukan sekedar mengajak manusia agar mereka menerima apa yang diserukan oleh seorang dai, bukan pula kepintaran seseorang berorasi di atas mimbar atau kemampuan menuangkan ide melalui tulisan. Lebih dari itu, dakwah merupakan hubungan seseoang secara horizontal dengan sesama yang bersifat saling mempengaruhi. Dari sini, ada sisi lain yang harus dimengerti oleh mereka yang mengemban amanat dakwah ini, mengingat bahwa kewajiban dan tanggung jawab seorang dai merupakan perkara yang sangat besar, apalagi kegiatan

${ }^{4}$ QS. al-Māidah (5): 48

${ }^{5}$ QS. Ali Imrān (3): 64 
dakwah dari masa ke masa, dari generasi ke generasi, bahkan dari abad ke abad, tentu sangat variatif, sebab akan ditemukan berbagai tantangannya.

\section{B. Pengertian Pluralitas dan Tantangan Dakwah}

Pluralistik dalam bahasa Inggris berasal dari kata plural (adj) berkaitan dengan dengan bentuk jamak (plural) lebih dari satu. Pluralistic juga pluralist (adj) dari kata plural (sifat), yaitu dari keragaman dalam sebuah komunitas masyarakat (dalam ilmu sosial), seperti keragaman ras, politik, agama dan kepercayaan. Keragaman itu terutama agama dan kepercayaan akan baik dan harmonis manakala para penganutnya dapat hidup bersama penuh kedamaian dalam suatu komunitas. ${ }^{6}$

Muhammad Imārah mendefinisikan pluralitas sebagai kemajemukan yang didasari oleh keunikan dan kekhasan. Pluralitas tidak dapat terwujud atau diadakan atau terbayangkan keberadaannya kecuali sebagai antitesis dan sebagai obyek komparatif dari keseragaman dan kesatuan yang merangkum seluruh dimensinya. ${ }^{7}$

Kata dakwah merupakan ism mas dar dari kata $d a^{\prime} \bar{a}$ yang dalam Ensiklopedia Islam diartikan sebagai “ajakan kepada Islam. Kata $d a$ ' $\bar{a}$ dalam Al-Qur'an, terulang sebanyak 5 kali, sedangkan kata yad'ū terulang sebanyak 8 kali dan kata dakwah terulang sebanyak 4 kali. ${ }^{8}$ Kata $d a$ 'a pertama kali dipakai dalam Al-Qur'an dengan arti mengadu (meminta pertolongan kepada Allah) yang pelakunya adalah Nabi Nuh

${ }^{6}$ English Dictionary, Oxford: Advanced Learner's Dictionary (Oxford University Press, UK, 2000), h.971

${ }^{7}$ Muhammad Imārah, al-Islām wa al-Ta'addudiyah; al-Ikhtilāf wa al-Tanawwu' fi Ithār al-Wihdah, diterjemahkan oleh Abdul Hayyie al-Kattanie dengan judul Islam dan Pluralitas; Perbedaan dan Kemajemukan dalam Bingkai Persatuan (Cet. I; Jakarta: Gema Insani Press, 1999), h. 9

${ }^{8}$ Lihat Muhammad Fū'ad 'Abd al-Bāqi, al-Mu'jam al-Mufahras li Alfāz al-Qur'ān alKarìm (Bairut: Dār al-Fikr, 2002), h. 330 
as. ${ }^{9}$ Lalu kata ini berarti memohon pertolongann kepada Tuhan yang pelakunya adalah manusia (dalam arti umum). ${ }^{10}$ Setelah itu, kata $d a$ ' $\bar{a}$ berarti menyeru kepada Allah yang pelakunya adalah kaum Muslimin. ${ }^{11}$

Syekh Ali Mahfudz menjelaskan bahwa dakwah mendorong manusia untuk berbuat baik, menurut petunjuk dan beramar makruf Nahi Munkar guna mencapai kebahagiaan hidup di dunia dan di akhirat. ${ }^{12}$ Sedangkan Bahy al-Huliy menyatakan dakwah adalah memindahkan suatu situasi manusia ke yang lebih baik. ${ }^{13}$

Dari uraian-uraian di atas, maka dapat dipahami bahwa kata dakwah dalam pengertian terminologi adalah menyeru, memanggil, mengajak dan menjamu. Adapun orang yang melakukan ajakan atau seruan tersebut dikenal dengan da'i (orang yang menyeru). Pada sisi lain, karena penyampaian dakwah termasuk tablīgh, maka pelaku dakwah tersebut di samping dapat disebut sebagai da'i, dapat pula disebut sebagai muballig yaitu orang yang berfungsi sebagai komunikator untuk menyampaikan pesan (message) kepada pihak komunikan. Jadi terminologis adalah mengajak umat manusia kepada al-khaer serta memerintahkan mereka berbuat ma'rūf dan mencegah berbuat munkar agar mereka memperoleh kebahagiaan hidup di dunia dan akhirat. Pengertian dakwah ini, berdasar pada QS. al-Imrān (3): 104 sebagai berikut ;

${ }^{9}$ QS. al-Qamar (54): 10

${ }^{10}$ QS. al-Qamar (39): 8

${ }^{11}$ QS. Fushshilat (41): 33

${ }^{12}$ Syekh Ali Mahfudz, Hidayat al-Mursyidin, (Mesir: Dar al-Kutub, 1952), h. 17

${ }^{13}$ al-Bahy al-Huliy, Tazkirat al-Du'at (Mesir al-Kitab al-Arabiy, 1952), h. 27 


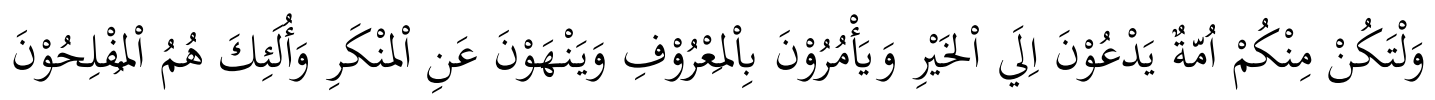

Terjemahnya :

Dan hendaklah ada di antara kamu segolongan umat yang menyeru kepada kebajikan, menyuruh kepada yang ma'ruf dan mencegah dari yang munkar, merekalah orang-orang yang beruntung. ${ }^{14}$

Proses dalam berdakwah tersebut diperhadapkan oleh berbagai tantangan, karena situasi masa kini telah berubah, dimana tindakan kaum Muslimin pun berubah. Banyak hal yang dilakukannya bertentengan dengan tuntutan Islam, kian hari kian menajam dan curam. Keadilan yang merupakan senjata dakwah Islam kini karatan dan lapuk di tangan mereka sendiri.15

Istilah pluralistik berkaitan dengan plural (jamak, keragaman). Jadi dakwah pluralistik yaitu ragam metode dakwah untuk menyampaikan risalah (Islam) kepada mad'udengan melihat dan memahami keragaman mad'u, meliputi keragaman organisasi politik, latar belakang pendidikan, ormas, mazhab dan agama serta perbedaan-perbedaan lainnya. Dengan dakwah pluralistik, da'i tidak mempersoalkan perbedaan hal-hal yang mendasar lainnya yang ada pada mad'u. Yang prinsip dan diutamakan adalah menjunjung tinggi akhlak mulia.

\section{Perdebatan seputar Pluralisme}

Gamal Al Banna dikenal sebagai seorang tokoh pembaruan fiqh di Mesir. Pembaruan yang dilakukan Gamal di bidang fiqh dipandang kontroversi. Pembaruan fiqh telah cukup lama menggelegar di dunia Islam. Pada bulan Desember 1995 al-Banna menggulirkan wacana pembaruan fiqh dengan

\footnotetext{
${ }^{14}$ Departemen Agama RI, al-Qur'an dan Terjemahnya (Jakarta: Proyek Pengadaan Kitab Suci al-Qur'an, 2002), h. 93.

${ }^{15}$ Demikian yang diungkap oleh Abū Zahrah, al-Da'wah Ilā al-Islām diterjemah-kan oleh H. Ahmad Subandi dan Ahmad Sumpeno dengan judul Dakwah Islamiyah (Cet.I; Bandung: Remaja Rosdakarya, 1994), h. 13.
} 
diluncurkan buku yang berjudul Nahwa Fiqhin Jadid (menuju fiqh baru) jilid pertama. Kemudian disusul dengan jilid kedua (1997), dan terakhir jilid ketiga (1999). Langkah Gamal langsung “menusuk" jantung persoalan; yaitu dasar hukum Islam. Sebagaimana dimaklumi, dasar hukum Islam yang populer selama ini adalah; al-Qur'an, Hadis, Ijma' dan Qiyas. Dengan buku ini Gamal merombak dan menata ulang dasar hukum Islam di atas menjadi; Akal, Nilai-nilai Universal Al-Qur'an, Sunnah dan Adat Istiadat. ${ }^{16}$

Konsep pluralitas (ta'addudiyah) adalah suatu hal yang wajar (sunnatullah) sebagaimana digali oleh al-Banna berdasarkan kenyataan pluralistik umat Islam, dan itu didasarkan pada konsep al-Qur'an. Al-Qur'an menyeru dan memberikan pemahaman otentik mengenai pluralisme. Gamal al-Banna mengulas masalah pluralitas dengan berpijak dari konsep dan prinsip penting dalam Islam, yaitu tauhid. Dengan konsep tauhid itu, Gamal al-Banna menyatakan bahwa selain Allah adalah nisbi dan plural. Hanya Allah yang Esa. Keyakinan demikian menurut Gamal al-Banna dapat menumbuhkan kesadaran bahwa kemutlakan hanya milik Allah, dan yang selain-Nya adalah plural. Ketauhidan yang benar akan membawa kesadaran terhadap pluralitas.

Gamal al-Banna ingin mempertegas bahwa mengakui keesaan Allah dan pluralitas dalam al-Qur'an, menunjukkan eksistensi pluralitas di dalam masyarakat berarti penegasan kepada prinsip utama dalam Islam, yakni tauhid kepada Allah. Pengakuan terhadap pluralitas berarti pengakuan terhadap adanya masyarakat

\footnotetext{
${ }^{16} \mathrm{Gamal}$ al-Banna adalah adik tokoh pendiri gerakan Islam sayap kanan Ikhwanul Muslimin di Mesir. Menurut Jalaluddin Rakhmat, Gamal al-Banna itu berubah dari seorang eksklusif menjadi pluralis. Lihat Jalaluddin Rakhmat, Islam dan Pluralisme (Jakarta: Serambi, 2006) h. 19
} 
(Muslim) yang tidak berwajah tunggal, monoton, dan stagnan, melainkan plural dan beraneka ragam. ${ }^{17}$

Pluralitas manusia sebagai sunnatullah, tidak akan bisa dihilangkan sampai kapan pun hingga akhir zaman. Dalam pluralitas terdapat makna perbedaan, persamaan, keberagaman yang sangat fitrah, universal dan abadi. Tanpa adanya pluralitas, manusia tidak akan mungkin meraih kesuksesan dan bahkan ia tidak mungkin dapat menjalankan kehidupan. ${ }^{18}$

Pluralitas merupakan karunia yang tetap memiliki nilai-nilai positif dan akan memperkaya sikap hidup bersama dan kompetisi yang sehat sebagaimana dalam alQur'an, yaitu berlomba-lomba dalam kebajikan.

Doktrin pluralis menyatakan bahwa semua pemeluk agama memiliki peluang yang sama untuk memperoleh keselamatan dan masuk surga berdasarkan kriteria masing-masing. ${ }^{19}$ Dalam buku Gamal al-Banna dinyatakan:

"Keberanian luar biasa dalam merampas wewenang Allah! Apakah mereka yang memegang kunci-kunci neraka? Apakah mereka yang menenggelamkan manusia ke dalam neraka? Atas dasar apa mereka membangun kesimpulan itu? Bagaimana kesadaran mereka atas rahmat Allah yang tidak terbatas yang membalas satu kebaikan dengan tujuh ratus lipat kebaikan? Kasih sayang seorang ibu hanyalah satu dari seratus kasih sayang-Nya. Dia tidak akan menenggelamkan manusia ke dalam neraka, kecuali manusia-manusia pembangkang yang berbuat kerusakan dan kezaliman di muka bumi. ${ }^{20}$

${ }^{17}$ Azyumardi Azra, "pengantar" dalam Gamal al-Banna, Pluralitas dalam Masyarakat Islam. terj., karya (Jakarta: MataAir, 2006), h. viii

\footnotetext{
${ }^{18}$ Ibid.

${ }^{19}$ Jalaluddin Rakhmat, Islam dan Pluralisme...., h. 20

${ }^{20}$ Gamal al-Banna, Doktrin Pluralisme dalam al-Qur'an (Bekasi: Menara, 2006), h. 41
} 


\section{Dakwah pada Masyarakat Plural: Peluang dan Tantangan.}

Masyarakat Islam yang plural menjadi bukti bahwa Islam adalah agama yang memiliki khazanah ajaran yang sangat kaya dan memberi peluang yang luas bagi umatnya untuk mengembangkan ajaran-ajaran agamanya sesuai dengan tuntutan zaman. Sebenarnya, masyarakat Islam yang plural, memiliki sisi-sisi negatif dan positif. Sisi negatifnya adalah terbukanya potensi disintegrasi di kalangan umat Islam karena gesekan-gesekan antar aliran dan kelompok seringkali tidak bisa dihindari. Gesekan-gesekan ini terkadang meningkat menjadi perseteruan tajam yang meretakkan hubungan antar umat Islam. Sisi positif dari masyarakat plural ini mestinya lebih ditonjolkan agar umat Islam terbiasa dalam suasana perbedaan tanpa harus saling mengklaim dan agar mereka dapat menjalankan dakwah islam dalam semangat fastabiq al-khairāt yang tinggi demi terwujudnya 'iz al-Islām wa alMuslimūn. Berkaitan dengan itu, maka pendekatan dakwah kultural yang berdasarkan ajaran Islam perlu dikelolah secara baik, terutama aspek materinya dan obyek dakwah itu sendiri.

Pendekatan dakwah menunjukkan hal yang signifikan antara materi dan objek dakwah. Terkadang materi dakwah kurang menarik audiens-nya karena terjadi kesenjangan antara materi dan obyek dakwah. Ketiga unsur ini sangat penting dilaksanakan dalam kegiatan dakwah di tengah-tengah masyarakat plural.

Urgensi dakwah oleh karena berdasar pada sejarah Nabi saw yang senantiasa melaksanakan dakwah dengan memperhati-kan situasi dan kondisi masyarakat yang dihadapinya ;

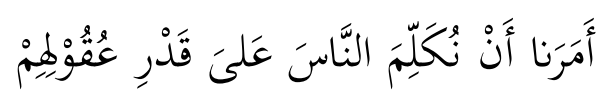

Artinya : 
Kami diperintahkan untuk berdialog, berbincang dan beraudiensi dengan manusia sesuai tingkat dan kadar intelektualnya.

Secara normatif, Islam telah memberikan petunjuk tentang pendekatan dakwah kultural dalam kerangka perannya yang antara lain men-jelaskan fungsifungsi yang diperankan oleh dakwah secara umum. Adapun dalil yang terkait dengan peran dakwah ini adalah QS. al-Ahzāb (33): 45-46

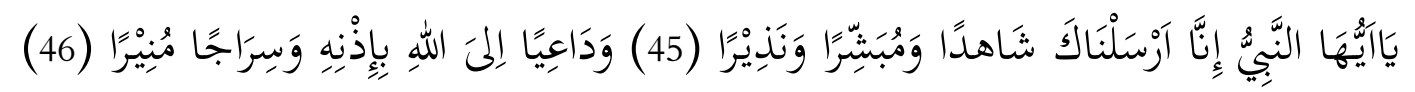

Terjemahnya :

Hai Nabi, sesungguhnya Kami mengutusmu untuk jadi saksi dan pembawa kabar gembira dan pemberi peringatan. Dan untuk jadi penyeru kepada agama Allah dengan izin-Nya dan untuk jadi cahaya yang menerrangi. ${ }^{21}$

Dari ayat tersebut pula, mengisyaratkan sekurang-kurangnya lima peran pendekatan dakwah, sebagai berikut :

1. Dakwah berperan sebagai syāhidan, artinya; dakwah harus berperan memberikan kesaksian kepada umat tentang masa depan yang akan dilaluinya sekaligus sejarah masa lalu yang menjadi pelajaran baginya tentang kemajuan dan keruntuhan umat manusia karena perilaku yang diperankannya

2. Dakwah berperan sebagai mubasysyiran, artinya; melalui dakwah maka akan saling memberi kabar gembira sekaligus saling memberikan inspirasi dan solusi dalam menghadapi berbagai masalah hidup dan kehidupan.

\footnotetext{
${ }^{21}$ Departemen Agama, op. cit., h. 675.
} 
3. Dakwah berperan sebagai nażīran, artinya; dakwah senantiasa ber-usaha mengingatkan para umat Islam untuk tetap konsisten dalam kebajikan dan keadilan sehingga tidak mudah terjebak dalam kesesatan.

4. Dakwah berperan sebagai dā'iyah ilā Allāh, artinya; dakwah adalah panglima dalam memelihara keutuhan umat sekaligus membina kualitas umat sesuai dengan idealisasi peradaban yang dikehendakinya.

5. Dakwah berperan sebagai sirājan munīran, artinya; dakwah memiliki peran sebagai pemberi cahaya yang menerangi kegelapan sosial atau kegersangan spritual.

Peran-peran dakwah yang disebutkan di atas, secara umum bermuara pada upaya pensosialisasian ajaran Islam di tengah-tengah masyarakat plural. Kaitannya dengan itu, Quraish Shihab menyatakan bahwa perwujudan dakwah bukan sekedar usaha peningkatan pemahaman keagamaan dalam tingkah laku dan pandangan hidup saja, tetapi juga menuju sasaran yang lebih luas. Yakni, dakwah harus lebih berperan menuju kepada pelaksanaan Islam secara lebih menyeluruh dalam berbagai aspek kehidupan. ${ }^{22}$

Urgensi dakwah yang dipaparkan di atas, keberhsilan dakwah bukanlah diukur lewat gelak tawa atau tepuk riuh para mustami' (pendengar dakwah), bukan pula dengan ratap tangis mereka. Tetapi sukses tersebut diukur lewat, antara lain pada tersosialisasinya ajaran Islam di tengah-tengah masyarakat plural. Dengan demikian, jelaslah bahwa pendekatan dakwah kultural memainkan peranan sangat penting.

\footnotetext{
${ }^{22}$ H.M. Quraish Shihab, Membumikan Al-Qur'an; Fungsi dan Peran Wahyu dalam Kehidupan Masyarakat (Cet. IX; Bandung: Mizan, 1994), h. 194
} 
Selanjutnya, mengenai masyarakat plural dalam hal agama-agama, juga merupakan problema fenomenal dalam penggunaan pendekatan dakwah kultural. Dikatakan demikian, karena watak agama secara umum yang ingin menyebarkan agamanya kepada orang lain; atau ingin "memaksakan" agar ajaran-ajaran agamanya teraplikasi dalam berbagai dimensi kehidupan, menjadi faktor yang cukup dominan bagi terjadinya ketidakharmonisan bahkan disintegrasi antar umat beragama, serta perseteruan antara umat beragama dengan wilayah-wilayah kehidupan profan.

Dakwah yang dikembangkan dalam masyarakat plural yang resisten terhadap konflik, bisa menimbulkan implikasi luas bila tidak dikemas dengan pendekatan dakwah kultural. Seorang dai bisa saja bertindak sebagai "provokator" terhadap umat dengan mengkorbankan semangat jihad sebagai tugas suci membela agama. Dalam kaitan ini, jihad dimaknai dalam artinya yang ekslusif, yaitu perang suci melawan non-Muslim (kafir) demi mepertahankan dan menegakkan agama Allah. Sebaliknya, bila si dai memahami makna jihad dalam arti luas dan menghayati makna Islam secara esensial, yaitu "menciptakan kedamaian" maka kemasan dakwah bisa lebih arif dan tidak selalu harus bersifat provokatif. Kapan jihad dimaknai secara ekslusif dan kapan dimaknai secara lebih luas merupakan pilihan yang arif dari seorang dai dengan melihat berbagai kondisi yang mengitari.

Ketegangan antara agama dengan wilayah-wilayah kehidupan profan muncul karena adanya semangat dari kaum agamawan, termasuk Islam, untuk "meng-agama-kan" kehidupan ini. Dalam Islam dikenal, istilah Islamisasi kehidupan yaitu, upaya untuk menerapkan ajaran-ajaran Islam dalam berbagai dimensi kehidupan. upaya islamisasi ini seringkali berbenturan dengan 
kepentingan-kepentingan kelompok tertentu yang merasa terusik dengan gerakan tersebut yang pada gilirannya memicu terjadinya konflik. Contoh kongkretnya adalah kasus RUU tentang Pornografi dan Pornoaksi yang digodok di DPR menimbulkan protes keras dari berbagai kalangan seniman yang tidak mau diatur oleh norma-norma lain di luar norma seni. Untuk menghindari terjadinya konflikkonflik seperti dimaksudkan, maka diperlukan kearifan mengemas pendekatan dakwah kultural sehingga upaya-upaya Islamisasi terhadap kehidupan dapat berjalan dengan baik.

Misi perbaikan umat yang menjadi tugas inheren dari penyebar agama mengharuskan untuk memberi perhatian yang lebih intens terhadap dinamika masyarakat yang dihadapi dengan cara, pendekatan agama melalui dakwah tetap merupakan model pendekatan yang selalu relevan untuk merespons problematika aktual seperti yang telah disebutkan, apalagi di tengah-tengah masyarakat Indonesia yang dikenal religius.

Dinamika dan tantangan dakwah di era ini mengharuskan para dai/muballig agama untuk bersama-sama mencari solusi bagi pemecahan dan bersikap proaktif untuk memberi respons demi tercapainya cita-cita dakwah. Para para penyebar agama dan isntitusi-institusi pengelolah dakwah harus menyadari bahwa tanggung jawab keberhasilan penyebaran agama ke depan berada di pundak mereka. Ini berarti kejayaan Islam ataupun kemundurannya di masa datang juga menjadi tanggung jawab yang harus dipikul secara bersama-sama.

Selanjutnya, para dai/muballig agama harus menyakini bahwa perbedaanperbedaan karena latar belakang organisasi, afiliasi politik, kecenderungan mażhab dan sebagainya, tidak harus menjadi penghalang bagi terwujudnya persatuan dan 
ukhuwwah yang dimaksud sebab pluralitas di tubuh umat adalah bagian dari dinamika yang justeru merupakan sunnatullah yang tidak dapat dan tidak harus ditolak ataupun dieliminasi.

Berkenaan dengan itu, para ulama, penyebar agama harus memegang prinsip utama, yakni; pertama, prinsip saling memahami dan menghormati dengan mengacu pada QS. al-Hujurat (49): 13,

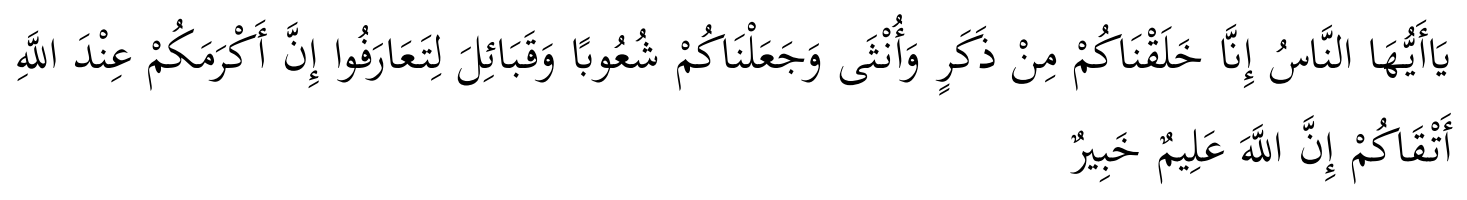

Terjemahnya :

Hai manusia, sesungguhnya Kami menciptakan kamu dari seorang laki-laki dan seorang perempuan dan menjadikan kamu berbangsa-bangsa dan bersukusuku supaya kamu saling kenal mengenal. Sesungguhnya orang yang paling mulia di antara kamu di sisi Allah ialah orang yang paling bertakwa di antara kamu. Sesungguhnya Allah Maha Mengetahui lagi Maha Mengenal. ${ }^{23}$

Kedua, adalah prinsip demokratisasi dengan mengacu pada beberapa ayat,

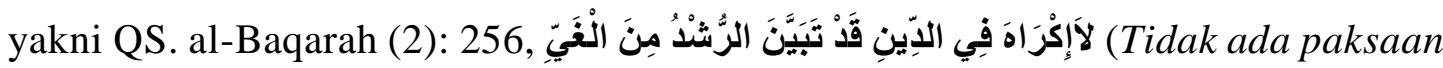
untuk (memasuki) agama (Islam); sesungguhnya telah jelas jalan yang benar daripada jalan yang sesat);24 QS. Yūnus (10): 99, أَفَنَتَتَ تُكْرِهُ النَّاسَ حَتَّى يَكُونُوا مُوْْمِنِينَ (maka apakah kamu (hendak) memaksa manusia supaya mereka menjadi orang-

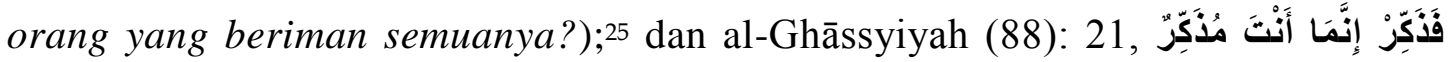
(Maka berilah peringatan, karena sesungguhnya kamu hanyalah orang yang memberi peringatan). ${ }^{26}$

\footnotetext{
${ }^{23}$ Departemen Agama RI, op. cit., h. 847

${ }^{24}$ Ibid., h. 63

${ }^{25}$ Ibid., h. 322

${ }^{26}$ Ibid., h. 1055
} 
Nabi saw telah memberi contoh, ketika beliau datang ke Madinah, tidak hanya mempersatukan suku Aus dan Khazraj, tetapi juga berhasil mempersatukan dan mempersaudarakan Muhajirin dan Anshar, serta mengayomi kaum Yahudi dan Nasrani dengan Piagam Madinah, maka pembinaan ukhuwah islamiyah perlu ditegaskan dengan empat tiang penyangga, yaitu; ta'āruf, tafāhum, ta'āwun, dan takāful. ${ }^{27}$

$T a$ 'āruf yakni saling mengenal, tidak hanya ta'āruf fisik atau biodata ringkas belaka, tapi lebih jauh lagi juga ta'āruf latar belakang pendidikan budaya, budaya, keagamaan, juga ta'āruf pemikiran, ide-ide, cita-cita, dan ta'āruf problem kehidupan yang dihadapi. Di samping itu, perlu juga adanya sikap tafāhum, yakni saling memahami kelebihan dan kekurangan, kekuatan dan kelemahan masingmasing, sehingga segala macam bentuk kesalahfahaman dapat dihindari.

Selanjutnya adalah ta'āwun, yakni saling tolong menolong, di mana yang kuat kuat menolong yang lemah, dan yang mempunyai kelebihan menolong yang kekurangan. Terakhir, adalah takäful yakni saling memberikan jaminan, sehingga menimbulkan rasa aman, yang pada akahirnya tidak ada lagi rasa kekhawatiran dan kecemasan menghadapi hidup ini karena ada jaminan dari sesama sudara untuk memberikan pertolongan.

\section{E. Kesimpulan}

Berdasarkan uraian-uraian sebelumnya, maka dapat suatu dirumuskan kesimpulan bahwa pluralitas adalah kemajemukan yang didasari oleh keunikan dan kekhasan. Pluralitas ini, memiliki kaitan dengan pelaksaan dakwah, sebab dalam

\footnotetext{
${ }^{27}$ Lihat Yunahar Ilyas, Kuliah Akhlaq (Cet. V; Yogyakarta: Lembaga pengkajian dan Pengamalan Islam/LPPI, 2002), h.223-224.
} 
proses berdakwah diperhadapkan oleh berbagai kemajemukan di tengah-tengah masyarakat plural.

Dakwah dalam masyarakat pluralis tetap harus berjalan yakni mengajak atau menyeru manusia dengan cara memperhatikan nilai-nilai budaya yang ada pada suatu masyarakat yang majemuk dan atau masyarakat yang beraneka ragam dengam berbagai kekhasannya. Masyarakat pluralitas harus dipahami sebagai pertalian sejati kebhinekaan dalam ikatan-ikatan keadaban. Oleh sebab itu, dengan pendekatan dakwah kultural, maka antara materi dan obyek dakwah sangat signifikan.

Tantangan dakwah masa kini sangat beragam sejalan dengan keadaan masyarakat yang plural, di mana sering terjadi konflik, dan bisa menimbulkan implikasi luas. Tantangan lain dari pelaksanaan dakwah di era ini adalah bahwa dakwah yang cukup menonjol tetapi ada kesenjangan antara gerakan dakwah di kota-kota dan di desa-desa, baik dari segi intensitas dan kuantitas maupun dari segi bobot dan kualitasnya. Oleh karena itu, dengan tantangan dakwah di era ini, mengharuskan para dai/muballig agama untuk bersama-sama mencari solusi bagi pemecahan dan bersikap proaktif untuk memberi respons demi tercapainya cita-cita dakwah. 


\section{REFERENCES}

Departemen Agama RI, al-Qur'an dan Terjemahnya. Jakarta: Proyek Pengadaan Kitab Suci al-Qur'an, 2002.

al-Banna, Gamal, Pluralitas dalam Masyarakat Islam. terj., karya (Jakarta: MataAir, 2006. , Doktrin Pluralisme dalam al-Qur'an. Bekasi: Menara, 2006.

Al-Bāqi, Muhammad Fū'ad 'Abd. al-Mu'jam al-Mufahras li Alfāzal-Qur'ān alKarìm. Bairut: Dār al-Fikr, 1992.

al-Huliy, al-Bahy, Tazkirat al-Du'at, Mesir al-Kitab al-Arabiy, 1952.

Departemen Pendidikan dan Kebudayaan, Kamus Besar Bahasa Indonesia, Edisi III. Cet. II; Jakarta: Balai Pustaka, 2002.

English Dictionary, Oxford: Advanced Learner's Dictionary (Oxford University Press, UK, 2000), h.971

Hafidhuddin, Didin. Dakwah Aktual. Cet.I; Jakarta: Gema Insani Press, 1998.

Haramain, Muhammad. "DAKWAH DALAM ARUS GLOBALISASI MEDIA: PELUANG DAN TANTANGAN." KOMUNIDA: MEDIA KOMUNIKASI DAN DAKWAH 7.1 (2017): 60-73.

Haramain, Muhammad. "الوسطية و أثر ها فى الدعوة الإسلامية (در اسة لغوية منهجية)" Langkawi: Journal of The Association for Arabic and English 2.1 (2016): 83-100.

Ulum, Ahmad Choirun, and Muhammad Haramain. "EKSISTENSI DAKWAH DALAM MERESPON PLURALISME." KOMUNIDA: MEDIA KOMUNIKASI DAN DAKWAH 7.2 (2017): 124-138.

Ilyas, Yunahar. Kuliah Akhlaq. Cet. V; Yogyakarta: Lembaga pengkajian dan Pengamalan Islam/LPPI, 2002.

Imārah, Muhammad. al-Islām wa al-Ta'addudiyah; al-Ikhtilāf wa al-Tanawwu' fi Ithār al-Wihdah, diterjemahkan oleh Abdul Hayyie al-Kattanie dengan judul Islam dan Pluralitas; Perbedaan dan Kemajemukan dalam Bingkai Persatuan. Cet. I; Jakarta: Gema Insani Press, 1999

Mahfudz, Ali, Hidayat al-Mursyidin, Mesir: Dar al-Kutub, 1952.

Muhammad Imārah, al-Islām wa al-Ta'addudiyah; al-Ikhtilāf wa al-Tanawwu' fi Ithār al-Wihdah, diterjemahkan oleh Abdul Hayyie al-Kattanie dengan judul Islam dan Pluralitas; Perbedaan dan Kemajemukan dalam Bingkai Persatuan (Cet. I; Jakarta: Gema Insani Press, 1999. 
Rakhmat, Jalaluddin, Islam dan Pluralisme. Jakarta: Serambi, 2006.

Shihab, H.M. Quraish. Membumikan Al-Qur'an; Fungsi dan Peran Wahyu dalam Kehidupan Masyarakat. Cet. IX; Bandung: Mizan, 1994.

Subandi, H. Ahmad dan Ahmad Sumpeno dengan judul Dakwah Islamiyah. Cet.I; Bandung: Remaja Rosdakarya, 1994. 